\title{
Pain Assessment as a Tool in Back-to-Work Rehabilitation
}

\author{
Aud Moe*, Aud Evensen, Karin Torvik, Hildfrid V. Brataas \\ Faculty of Health Science, Nord-Trøndelag University College, Steinkjer, Norway \\ Email: ªud.moe@hint.no, AudEmelie.Evensen@hint.no, Karin.Torvik@hint.no, hildfrid.brataas@hint.no
}

Received 17 August 2015; accepted 25 September 2015; published 28 September 2015

Copyright (C) 2015 by authors and Scientific Research Publishing Inc.

This work is licensed under the Creative Commons Attribution International License (CC BY). http://creativecommons.org/licenses/by/4.0/

(c) (i) Open Access

\section{Abstract}

The purpose of this study was to elucidate participant experiences with a way to use pain assessment as a tool in vocational rehabilitation and see if the process is perceived to be important for the rehabilitation process in a four-week lasting rehabilitation back to work program for people with chronic pain, mental illness and fatigue symptoms. Design: A qualitative study. Purposeful typical case sampling. Semi-structured qualitative interviews with rehabilitation back to work participants were thematic content analyzed. Setting: Interviews at the end of the $4^{\text {th }}$ week of rehabilitation took place at a Rehabilitation Center in Central Norway. Subjects: Six women and four men aged 23 to 57 years, suffering from chronic pain and mild mental illness symptoms. Main outcome measure: This paper describes the participants' experiences with pain mapping in backto-work rehabilitation, used as a tool in a rehabilitation model for people suffering from chronic pain and mild mental illness. Results: The main topic was "empowered to insights". The results illustrate a process where mapping tools were experienced relevant in the process of growing discovery of pain and ways of pain management. Pain assessment as a joint aid for both themselves and the staff provided a clearer pain understanding. Conclusion: Mapping as own activity, and cooperation with supportive personnel showing respect for patients' own experiences, may promote empowerment, and further motivate own efforts and progress of the rehabilitation process.

\section{Keywords}

Pain Assessment, Rehabilitation to Work, Empowerment, Qualitative Research

\section{Introduction}

The article deals with a study of participants’ experiences when using pain assessment as a tool in back-to-work

*Corresponding author. 
rehabilitation called Responsibility for Self-Mastery (AFEM) [1] for people on sick leave who have compound problems, such as chronic pain, musculoskeletal disorders, psychological distress, and signs of fatigue. AFEM is a comprehensive four-week lasting psychosocial and psycho-educative rehabilitation back to work program in Central Norway [2]. The model includes pain assessment and total appraisements based on the International Classification of Functioning, Disability and Health model (ICF) [3]. Based on this health understanding, participants' pain experiences can be understood as complex, with links between biological, psychological, and social aspects of the experience [4] [5]. According to an agreement with The Central Norway Regional Health Authority, the AFEM rehabilitation model from 2007 is used as a specialist health measure for people on sick leave in Mid-Norway [6].

A comprehensive pain assessment can be used in biomedical and psychosocial domains [7]. In the assessment of chronic musculoskeletal pain, quantitative tools [8] and health-related quality of life instruments [9] can be used, since pain may affect quality of life [10]. The pain phenomenon can be understood as personal experience, and consequently only the person experiencing pain may fully assess the pain character and intensity. Therefore, self-reporting is seen as valid pain assessment [11].

Rehabilitation for workers with musculoskeletal pain have shown improvement in participants' employability and job performance through their development of pain self-efficacy [12]. From an empowerment perspective [13], self-reporting and pain assessment instruments may both strengthen the patient involvement and his/her pain self-efficacy. The patient's perception of involvement and control are key components of empowerment in rehabilitation [14]. Wikman and Fältholm [15] studied patient empowerment and found that support from health professionals was of significance for the patients' involvement in their rehabilitation.

Experience creates expectations, and our expectations are important for what we perceive [16]. Lillrank [17] found that women with chronic pain had the experience that some doctors did not take subjective pain seriously when diagnosing chronic pain. Other studies, however, have shown the positive and supportive attitudes of health professionals [15] [18] [19]. A study conducted by Coutu et al. [20] showed that being met with positive attitudes led to a changed way of thinking about pain [20]. This may show that professionals' communication of attitudes may have an impact on how patients perceive the world [16] [21] and own pain. Expectations and thoughts concerning pain appear to have an impact on perception of pain. In anticipation of pain, one can easily perceive something painful. For the chronically ill, the perspectives "illness-in-foreground" and "wellness-inforeground" may have specific functions in the person's world [22] [23]. A life with chronic ailments can be an ongoing and changing process, where the focus is mainly on pain rather than on well-being. Is it, in that case, possible to turn over the perspective? Does the pain assessment further pain focus, or vice versa-does it put painful focus in the background, and focus on what brings well-being in life? How pain is focused, and how are the pain assessment activities experienced in the context of AFEM back-to-work rehabilitation?

Little has been studied about participant experiences of the pain assessment in vocational rehabilitation; nothing has been studied in the AFEM rehabilitation arena. Experience-based knowledge about pain assessment may be important for further development and use of assessment in rehabilitation for individuals with chronic pain. The purpose of this study was to elucidate participant experiences with a way to use pain assessment as a tool in vocational rehabilitation and see if the process is perceived to be important for the rehabilitation process.

\section{Method}

The study had a qualitative descriptive and interpretive design, with individual interviews about the informants' experiences of pain assessment in the rehabilitation process. Analyses of interview data were done by content analysis in order to integrate narrative information in relation to key concepts and themes [24]. The research team had experience as researchers and as nurses in various areas of health care, including rehabilitation, chronic pain, and mental health care.

\section{Pain Assessment used in AFEM rehabilitation}

Pain assessment was carried out at three different times: before the person came to rehabilitation, in the first week, and in the last week (week 4) of the rehabilitation program. Assessment of pain was carried out using the SF-36 Health Survey (two questions of pain) [10], and the Brief Pain Inventory [25].

The SF-36 Health Survey, SF-36 [10] [26] [27] is a health and quality of life assessment tool with indexes of physical functioning, bodily pain, general health, physical vitality, social and emotional functioning, and mental health. One question was about bodily pain and one about how bodily pain affect every day work and activities. Responses are based on a Likert scale. 
Brief Pain Intervention [25] identifies pain, pain intensity, daily variation, and how pain affects the patient's functioning in relation to daily life. The form has one input issue that maps whether or not the patient has pain. The form includes a body map where the participant marks the pain areas on the body. Questions concerning daily variation and impact of pain on the patient's functional level is relative to the last 24 hours. All variables scored are by means of an 11-point numeric scale. Participants may fill out these forms without any help from the staff.

\section{Sample and sampling}

Purposeful sampling focuses on selecting information-rich cases that will shed light on the question under study [28]. Among the population that had chronic pain in Mid-Norway, the sample represented a selected group admitted as patients in the AFEM rehabilitation program. Approximately 40 people have attended AFEM rehabilitation annually since 2007. The inclusion criteria for the study were persons on sick leave with pain who participated in the AFEM rehabilitation. The informants reported idiopathic unexplained pain. Selection of informants for the study was carried out as "Typical case sampling” [24] [28] of persons holding key information about typical assessment experiences at this rehabilitation. Twelve rehabilitation participants were requested. Ten agreed to participate in the study, of which six were women and four were men, aged 23 years to 57 years. Before the stay at the rehabilitation institution the informants had been on sick leave from one month to several years.

\section{Data Collection}

Data was collected during 2013. Interviews were carried out by the first, second, and fourth authors and took place at the rehabilitation institution the last week of the rehabilitation program (week 4). To talk undisturbed, the interviewer and the interviewee withdrew from the arena where the rehabilitation activities took place. The interviewer asked open-ended questions, and the interviewees spoke about their experiences of pain assessment and the importance of the use of assessment tools in the rehabilitation process. A semi-structured interview guide began with questions related to pain assessment before admission. Then, the informants were encouraged to talk about the meaning of pain assessment as they experienced this at the end of the rehabilitation program. Finally, the interviewer opened the conversation for suggestions about the improvement of pain assessment practices at the clinic. The duration of the interviews was 20 - 30 minutes. The interviews were recorded on a digital recorder and thereafter transcribed to text.

\section{Data analysis}

Transcribed texts were analyzed by content analysis to determine the content and meaning of the stories; this method was inspired by Graneheim and Lundman [29]. The analysis started with reading the entire text several times to obtain an overall impression. The next step was to identify meaning units that were relevant for the study's purpose. Next, the units of meaning were condensed into condensed text, which were subsequently coded. "Labelling a condensed meaning unit with a code allows the data to be thought about in new and different ways” [29]. The codes were compared for similarities and differences, and sorted into six sub-categories under three categories that emerged from the manifest content. Two researchers performed independently analysis of subcategories, categories and development of theme. In order to validate the subcategories, categories and themes independently, the findings were compared. Thereafter, all four researchers participated in meetings where the analysis of meaning unit, categories, and theme discussed were until there was agreement on a common result formulation. The researchers reflected on the latent underlying meaning at an interpretative level based on the relationship or "thread" in the manifest content, expressed as sub-categories and categories [29]. From this analysis, a theme emerged as an overarching pattern in the material ref. Table 1.

Table 1. Subcategories, categories, and theme.

\begin{tabular}{|c|c|c|}
\hline Subcategory & Category & Theme \\
\hline $\begin{array}{l}\text { Relevance of the pain assessment tools } \\
\text { User-friendliness of the pain assessment tools }\end{array}$ & Charting of pain & \\
\hline $\begin{array}{l}\text { Participation through collaboration } \\
\text { Complicity through involvement }\end{array}$ & Discovery through participation & $\begin{array}{l}\text { Empowerment to own } \\
\text { insights }\end{array}$ \\
\hline $\begin{array}{l}\text { Awareness through notes making and reflection } \\
\text { Increased understanding of own pain }\end{array}$ & $\begin{array}{l}\text { Pain clarification and development of } \\
\text { own insights }\end{array}$ & \\
\hline
\end{tabular}




\section{Ethical considerations}

Permission to conduct the study was given from the Regional Committee for Medical and Health Research Ethics, Region Central (2013/534). The Head of Administration for the rehabilitation institution was informed about the project. He informed the participants verbally, gave them written information from the researchers, and requested participation in the study. Participants were informed of the possibility to withdraw from the study at anytime; they were also informed the study would have anonymity, confidentiality, and the use of de-identification of the information gathered through interviews. Participants gave written informed consent to participate before the interviews started.

A request communicated by the Head of Administration could be perceived as pressure to participate in the study, although the manager was not responsible for the rehabilitation program. To ensure voluntary participation, the researcher repeated the information about the request and the opportunity to withdraw from participation before the interviews started. Ten of the twelve subjects requested agreed to participate. The Head of Administration was not aware of who did not wish to participate.

\section{Findings}

From the interviews with the ten AFEM rehabilitation participants, the following categories emerged: Charting of pain, Discovery through participation, and Pain clarification due to assessment experiences. From further interpretation the theme "Empowered to own insights" emerged.

\section{Charting of pain}

Charting of pain was described as mapping headaches; neck pain; pain in the arms, shoulders, legs, pelvis, lower back, and knees; and stomach pains. Some also reported to have a deep inner pain of grief and despair. It could be difficult to distinguish between physical and psychological pain.

One of the forms used offsets, whereas the second additionally provided an opportunity for marking on a bodymap. The ability to visualize the pain was relevant to establish the location of the physical pain. One of the participants filled out the survey tool far in advance of their stay at the institution, and thought it was not very relevant. Another participant felt he really did not have much pain and there was little to chart. Still another had a lot of pain when they charted before the rehabilitation started.

Most participants had not thought of the importance of the assessment, but on reflection argued that the assessment was well done this way. Mapping tools encompassed the ability to identify the pain as it was experienced, and the tools were considered accurate and detailed. The tools provided an opportunity to see the logic in using them; they were relevant as part of the overall rehabilitation program. There was no one who proposed amendments to this charting of pain.

Charting pain meant that participants appreciated the ease of use of the tools. User-friendliness was about the design of the questionnaires. Shading pain areas on a drawing was especially appreciated and motivated participation in mapping:

"I could see on the drawing where I crossed and scribbled. It was really just thinking about it - and then I

knew it. This was the smartest way to show the pain, rather than just describe the pain”

Through illustrations and grading the questions, they received options to answers that they could relate to. User-friendliness also was strengthened by the fact that the mapping went quickly with little expenditure of time.

Participants who experienced much pain thought the charting tools were relevant, because they made their experiences and reflections of pain location specific and highlighted the complexity of the pain.

\section{Discovery through participation}

Discovery through participation in the charting process revolved around the patient; they had the opportunity to do the charting by self-report. The fact that the rehabilitation nurses wanted information and that the participants could fill it out on their own was a motivating experience, even before rehabilitation. This gave them a sense of positive and helpful attitudes among the staff.

In the pain assessment, done at the start of rehabilitation, their own participation and involvement varied. Some had not filled out the form, but conversed about pain assessment with employees. Others had filled out the form in collaboration with the staff, and some had been independent in filling out charting forms. At that time, participants regarded pain mapping as a tool for employees in their work. 
All participants experienced equality among the staff, and they showed confidence in them. Such confidence strengthened informants' trust in the employees and the overall rehabilitation program. Pain assessment was marked by the respect that boosted participants' confidence and self-respect.

When participants were shown that an interest in the knowledge of their own pain experience was in demand, they did not feel left to themselves. Doing pain assessments during their stay in the institution actualized the relationship with the rehabilitation nurse as an active helper. Thus, the assessment was an activity of importance in cooperation with the recovery process:

"We collaborate. I can fill out, and then I am in the process itself. You are not 'overrun' at a single point.

You are constantly a part of the process."

Personalized complicity built on mutual trust and support from competent helpers helped participants realize they were participants in the rehabilitation process.

At first, they had looked at mapping as a tool for employees. Eventually, they considered pain assessment as an aid in collaboration between the participant and staff. Participants went from passive participation to active participation through collaboration and "good relations".

\section{Pain clarification and development of own insights}

For one participant this experience was about raising awareness through the recording and reflection of writing and drawing on paper, which led to an awareness of the situation as it was. Records could even provide insight, and as a result, some of the informants had "laid down" exhausting thoughts that influenced pain. Regarding what one had experienced "at a distance", this provided a fresh start by going back to what made sense before the pain experiences.

Pain clarification also meant raising awareness through the experience of change, which appeared to some at the beginning of the stay:

"Good to see if one thinks of that pain map when coming to rehabilitation, I see how it has changed. One becomes conscious of that. Because I did not think about that anymore and I did not have that kind of pain to map any longer."

Another talked about awareness through repeated assessments:

"It was quite funny, really - because I saw the difference, but I did not think of it until a few days after I had filled it out. At that time the pain had begun to quit-then I thought about it-when I was going to fill it out and look over it again — then I saw it—I had no more pain.”

Some felt that raising awareness through mapping experiences could be utilized for even more active participation in the use of the forms under the rehabilitation process. To be aware of one's own pain was all about "raising awareness of body and mind", as expressed. Pain assessment could also be helpful in placing their responsibility on suffering, accountability, and self-awareness. This could in turn, result in a feeling of greater control over the situation.

The general theme for the three categories was "Empowered to own insights".

\section{Discussion}

The purpose of this study was to elucidate participant experiences with a way to use pain assessment as a tool in vocational rehabilitation and see if the process is perceived to be important for the rehabilitation process. The result illustrates a process through the participants' pain mapping and their use of relevant tools. The active participation led to an emerging discovery that the assessment could be a common aid for both patient and staff. Through these experiences a new awareness emerged and led to a deeper and more holistic understanding of their own pain situation. The topic "Empowered to own insights" demonstrated relationships between categories.

Charting of pain may be useful in routine assessments that can relate to other problems, such as physical functioning, emotional functioning, and the different experiences of satisfaction and quality of life [9]. Standardized self-report instruments to assess patients' pain [7] were experienced as relevant tools for the way they were used in AFEM rehabilitation. Personalized involvement built on mutual trust was, in this study, a support from the rehabilitation nurse that helped patients discover themselves as participants with their own responsibili- 
ties in the rehabilitation process.

Several studies [15] [18] [30] [31] point out that the process meetings for people with chronic pain are important for the experience of being respected and taken seriously. In this study participants discovered thorough participation. Empowered thinking requires that personnel have basic confidence in the individual's ability to make decisions and act in their best interest. Individually oriented empowerment is all about to initiation processes in order to boost confidence, knowledge, and skills [32]. Doas [21] found that actively listening can improve personal relationships and foster trust, mutual respect, and patient compliance. The trust that the participants were shown through repeated self-reports and conversations about pain assessment seemed to support a gradual build-up of more self-confidence and self-respect. The mapping tools used in communication with the rehabilitation nurse appear to be both trustworthy and lead to the development of insight. Communication and the nurse's behavior seem to be central to the participants' sense making processes [16]. Personnel appear to signal basic confidence that patients themselves can take responsibility and be active in the acquisition of knowledge about themselves, their pain, and perspectives on life. Mutual trust and respect are essential in the relationship between patient and health professionals [16] [19]. To be confirmed as a whole person, and not identified with a disorder, can be a force for patient participation [16] and for raising awareness of their own thinking. It is through the development to find individual strength and confidence that the individual realizes their resources and acquires more power and control over their lives [13].

The participants in this study experienced pain clarification and development of own insights through the rehabilitation process. Lillrank [17] found that when patients who previously had not been taken seriously for their subjective experience of pain, met health professionals who took their pain seriously, it was a turning point that could lead to "solve the puzzle" of the troublesome pain. Suffering can be enhanced and extended in duration by the stigma of pain, but troublesome pain can be changed if the person with pain is taken seriously [15] [17] [19].

Experiences of chronic pain appear to be shaped by biomedical and psychosocial factors [3] [7] [33]. The two assessment tools used in the study reflect these factors [10] [25]. When participants map their pain experiences, what proceeds comes from their individual background and understanding and shapes their interpretation in the context of their understanding of an ongoing order in life [16]. They do not deal with the world event by event, but rather frame events in larger meaning structures that provide them with an interpretive template within which they can make sense of relevant aspects of the events they experience [34]. During the assessment process a reflection process occurs; during this they make sense of their pain experiences, and a new, expanded selfknowledge seems to develop. A new way of thinking can be constructed through the experience of control [20]. A "turning point" is when the meaning of the experiences of the past and the individual's identity lead to new insights [17]. Research shows that workers on sick leave who returned to work after a rehabilitation program underwent an "illness-transformation", where their illness identity was abandoned because they experienced control of symptoms through pain management [20]. By spending time and attention to pain mapping, awareness of pain character and intensity may appear [11]. Positive results through a work rehabilitation program are shown as a reduction in pain intensity by developing a new way of thinking that changes the perception of pain [20]. This study's results show a new way of thinking in the sense of being more aware of both detail and comprehensiveness in their own pain experience by being empowered to own insights.

On the one hand, individual-oriented empowerment-thinking is criticized; health is seen as an "instrument" to get patients to act differently by adopting established knowledge (i.e., knowledge that the nurse holds) [13]. On the other hand, Anderson and Funell [35] argue that the empowerment to own insights represents a health promotion of thinking that has led to a paradigm shift among health care workers. Our findings about the raising of awareness through the experience, education, and empowerment that the participants in the rehabilitation experience supports the assumption of a paradigm shift-a shift that includes and values the patient's thinking.

\section{Method discussion}

The study provided information about how persons within a selected group participating at a specific rehabilitation program perceived use and usefulness of pain assessment scheme employed. Transferability consideration should be in light of the sample character, the rehabilitation arena, and the Central Norwegian context. The mapping tools do not specifically relate to the rehabilitation model. Therefore, the assessment experiences may be of relevance when considering mapping in other arenas.

To protect participants' anonymity, omitted are diagnoses, occupations and personal information. The study included a small sample and short stories, but the material was rich enough to get data about categories creating coherence within the main theme. More informants and redundant conversations could possibly provide more 
and detailed information about the topic. In the analysis of meaning units, the researchers were aware that interviews swung between experiences with mapping and experiences with the overall AFEM rehabilitation program. Through joint reflection among scientists, consensus emerged on relevant units of meaning. Credibility handled was through a detailed description. The analysis process, in which four researchers participated, strengthens the study reliability.

\section{Conclusions}

Pain assessment tools mapped physical pain, while notes, reflections, and collaboration with the rehabilitation nurse helped participants to reflect more holistic on pain experiences, this seemingly influencing a change in pain understanding and focus. Awareness and self-knowledge seemed promoted through an individually managed mapping, assessment, and through collaboration with the rehabilitation staff, this taking place in an empowerment process. Trust and respect led to the experience of involvement in the individual's rehabilitation process.

The participants had no suggestions for changes to the mapping practice. On the other hand, assessment possibly to greater extent could be used. There is a need for more knowledge about the importance of individual pain assessment as a tool for raising awareness, increasing control, and changes that may promote rehabilitation back to work.

\section{Author Contributions}

Study design: Aud Moe and Hildfrid V. Brataas. Data collection: Aud Moe, Aud Evensen and Hildfrid V. Brataas. Analyses and manuscript preparation: All four authors; Aud Moe, Aud Evensen, Karin Torvik, Hildfrid V. Brataas.

\section{Sources of Support}

The study was supported by Central Norway Regional Health Authority; Smednestrivselsgåd as, N 6590 Tustna, Norway.

\section{References}

[1] Indergaard, E. (2002) AFEM Model 2002. http://www.smednes-trivselsgard.no/afem-rehabilitering/afem-modellen

[2] Evensen, A., Brataas, H.V. and Landstad, B. (2010) Individuell læring i psykoedukativkognitiv rehabilitering. Nordisk Tidsskrift for Helseforskning, 6, 70-83.

[3] World Health Organization (2001) International Classification of Functioning, Disability and Health. WHO, Genova.

[4] Butler, D. and Moseley, L. (2008) Explain Pain. NOI Group. http://www.noigroup.com/en/Product/EPBII

[5] Garguilo, H., McCaffrey, R. and Frock, T.L. (2003) Understanding Chronic Pain and the Mindbody Connection. Holistic Nursing Practice, 6, 281-289.

[6] Norway. Helse Midt-Norge. Raskere tilbake (Fasterreturn). (2014). http://www.helse-midt.no/no/Pasient/Behandlingstilbud/Raskere-tilbake/84352/

[7] Dansie, E.J. and Turk, D.C. (2013) Assessment of Patients with Chronic Pain. British Journal of Anaesthesia, 111, 19-25.

[8] Chapman, J.R., Norvell, D.C., Hermsmeyer, J.T., Bransford, R.J., DeVine, J., McGirt, M.J. and Lee, M.J. (2011) Evaluating Common Outcomes for Measuring Treatment Success for Chronic Low Back Pain. SPINE, 36, S54-S68.

[9] Salaffi, F., Ciapetta, A. and Carotti, M. (2012) Pain Assessment Strategies in Patients with Musculoskeletal Conditions. Reumatismo, 64, 216-229. http://dx.doi.org/10.4081/reumatismo.2012.216

[10] Ware, J.E. and Sherbourne, C.D. (1992) The MOS 36-Item Short-Form Health Survey (SF-36). Medical Care, 30, 473-483. http://dx.doi.org/10.1097/00005650-199206000-00002

[11] International Association for the Study of Pain (2013) http://www.iasp-pain.org

[12] de Vries, H.J., Reneman, M.F., Groothoff, J.W., Geertzen, J.H.B. and Brouwer, S. (2013) Self-Reported Work Ability and Work Performance in Workers with Chronic Nonspecific Musculoskeletal Pain. Journal of Occupational Rehabilitation, 23, 1-10. http://dx.doi.org/10.1007/s10926-012-9373-1

[13] Askheim, O.P. (2012) Empowerment i helse-og sosialfaglig arbeid: Floskel, styringsverktøy eller frigjøringsstrategi (Empowermentin Healthand Social Work: cliché, managementorreleasestrategy)? Gyldendal Akademiske, Oslo. 
[14] Zimmerman, M.A., Israel, B.A., Schulz, A. and Checkoway, B. (1992) Further Explorations in Empowerment Theory: An Empirical Analysis of Psychological Empowerment. American Journal of Community Psychology, 20, 707-727. http://dx.doi.org/10.1007/BF01312604

[15] Wikman, A.M. and Fältholm, Y. (2006) Patient Empowerment in Rehabilitation: Somebody Told Me to Get Rehabilitated. Advances in Physiotherapy, 8, 23-32. http://dx.doi.org/10.1080/14038190500494774

[16] Hargie, O., Brataas, H.V. and Thorsnes, S.L. (2009) Cancer Patients' Sensemaking of Conversations with Cancer Nurses in Outpatient Clinics. Australian Journal of Advanced Nursing, 26, 70-78.

[17] Lillrank, A. (2003) Back Pain and the Resolution of Diagnostic Uncertainty in Illness Narratives. Social Science \& Medicine, 57, 1045-1054. http://dx.doi.org/10.1016/S0277-9536(02)00479-3

[18] Rørtveit, K., Hansen, B.S., Leiknes, I., Joa, I., Testad, I. and Severinsson, E. (2015) Patients’ Experiences of Trust in the Patient-Nurse Relationship-A Systematic Review of Qualitative Studies. Open Journal of Nursing, 5, 195-209. http://www.scirp.org/journal/ojn http://dx.doi.org/10.4236/ojn.2015.53024

[19] Nordin, C., Gard, G. and Fjellman-Wiklund, A. (2013) Being in an Exchange Process: Experiences of Patient Participation in Multimodal Pain Rehabilitation. Journal of Rehabilitation Medicine, 45, 580-586. http://dx.doi.org/10.2340/16501977-1136

[20] Coutu, M.-F., Baril, R., Durand, M.-J., Cote, D., Rouleau, A. and Cadieux, G. (2010) Transforming the Meaning of Pain: An Important Step for the Return to Work. 35, 209-219.

[21] Doas, M. (2015) Are We Losing the Art of Actively Listening to Our Patients? Connecting the Art of Active Listening with Emotionally Competent Behaviors. Open Journal of Nursing, 5, 566-570. http://www.scirp.org/journal/ojn http://dx.doi.org/10.4236/ojn.2015.56060

[22] Moe, A., Enmarker, I. and Hellzén, O. (2012) Daily Life for Chronically Ill Oldest Old Persons. Nursing Reports, 2, e8.

[23] Paterson, B.L. (2001) The Shifting Perspectives Model of Chronic Illness. Journal of Nursing Scholarship, 33, 21-26. http://dx.doi.org/10.1111/j.1547-5069.2001.00021.x

[24] Polit, D.F. and Beck, C.T. (2012) Nursing Research: Generating and Assessing Evidence Fornursing Practice. 9th Edition, Wolters Klüwer, Phladelphia.

[25] Klepstad, P., Loge, J.H., Borchgrevink, P.C., Mendoza, T.R., Cleeland, C.S. and Kaasa, S. (2002) The Norwegian Brief Pain Inventory Questionnaire: Translation and Validation in Cancer Pain Patients. Journal of Pain and Symptom Management, 24, 517-25. http://dx.doi.org/10.1016/S0885-3924(02)00526-2

[26] Ware Jr., J.E., Kosinski, M. and Keller, S.K. (1994) SF-36 Physical and Mental Health Summary Scales: A User’s Manual. The Health Institute, Boston.

[27] Ware Jr., J.E. (2011) SF-36 Health Survey Update. http://www.sf-36.org/tools/SF36.shtml

[28] Patton, M.C. (2002) Qualitive Research \& Evaluation Methods. 3th Edition. http://onlinelibrary.wiley.com/cochranelibrary/search.

[29] Graneheim, U.H. and Lundman, B. (2004) Qualitative Content Analysis in Nursing Research: Concepts, Procedures and Measures to Achieve Trustworthiness. Nurse Education Today, 24, 105-112. http://dx.doi.org/10.1016/j.nedt.2003.10.001

[30] Andersson, S., Sundberg, T., Johansson, E. and Falkenberg, T. (2012) Patients' Experiencesand Participations of Integrative Care for Back and Neck Pain. Alternative Therapies, 18, 25-32.

[31] Drachler, M.L., Leite, J.C., Hooper, L., Hong, C.S., Pheby, D., Nacul, L., Lacerda, E., Campion, P., et al. (2009) The Expressed Needs of People with Chronic Fatigue Syndrome/Myalgic Encephalomyelitis: A Systematic Review. BMC Public Health, 11, 458. http://dx.doi.org/10.1186/1471-2458-9-458

[32] Askheim, O.P. (2011) Pasientopplæring og empowerment (Patient educationandempowerment). In: Brataas, H.V., Ed., Sykepleiepedagogisk praksis (NursingEducationalPractice), Gyldendal Akademiske forlag, Oslo, 71-100.

[33] Fagermoen, M.S. and Lerdal, A. (2011) Teoretiske modeller for læring og mestring (Theoreticalmodelsfor Learning Andmastering). In: Lerdal og Fagermoen, ed., Læring og mestring-et helsefremmende perspektiv i praksisogforskning (Learning and Mastering-A Health Promotion Perspective in Practice and Research). Gyldendalakademisk, Oslo, 17-37.

[34] Mills, C. (2009) A Case of Making Sense of Organisational Communication. In: Hargie, O. and Tourish, D., Ed., Auditing Organisational Communication: A Handbook of Research, Theory and Practice, Routlede, London, 370-390.

[35] Anderson, R.M. and Funell, M.M. (2010) Patient Empowerment: Myths and Misconceptions. Patient Education and Counseling, 79, 277-282. http://dx.doi.org/10.1016/j.pec.2009.07.025 